\title{
The role of COST Actions in unifying the European ionospheric community in the transition between the two millennia
}

\author{
Bruno Zolesi ${ }^{1}$ and Ljiljana R. Cander ${ }^{2}$ \\ ${ }^{1}$ Istituto Nazionale di Geofisica e Vulcanologia, Rome, Italy \\ ${ }^{2}$ Rutherford Appleton Laboratory, Harwell Oxford, OX11 0QX, UK \\ Correspondence: Bruno Zolesi (bruno.zolesi@ingv.it)
}

Received: 13 December 2017 - Revised: 3 April 2018 - Accepted: 22 April 2018 - Published: 18 May 2018

\begin{abstract}
This paper consists of a review of the important contributions of four COST (European Co-operation in Science and Technology) Actions in the period 1991-2009 to terrestrial ionospheric research, with applications in modern communication and navigation systems. Within this context, new ionospheric studies were initiated, leading to the development of a number of models, algorithms for prediction, forecasting, and real-time specification, as well as numerical programs. These were successfully implemented in different collaborative projects within EU instruments, promoting co-operation between scientists and researchers across Europe. A further outcome was to bring together more than a hundred researchers from around 40 scientific institutions, agencies, and academia in about 25 countries worldwide. They collaborated with enthusiasm in research, as briefly described in this paper, forming a lively ionospheric community and presenting a strong intellectual response to the rapidly growing contemporary challenge of space weather research.
\end{abstract}

\section{Introduction}

The Earth's ionosphere is subject to great spatial and temporal variations. These include systematic changes in ionospheric characteristics and parameters according to the time of day, season, and solar epoch, and with significant spatial variations over hundreds of kilometres. There are also major irregular variations under specific circumstances, both from day to day at a given hour and even from minute to minute within an hour. Spatial gradients on single days are typically greater than the corresponding gradients in monthly median values. Ionospheric response to impulsive events from the Sun above, and from the neutral atmosphere below, varies from large-scale features to the creation of smaller scale irregularities. It is important to understand and model some of the these ionospheric structures in order to assess the environmental propagation effects for terrestrial high-frequency (HF) and Earth-space radio and navigation links, as well as for solar-terrestrial studies.

A wide variety of methods for ionospheric mapping and modelling of the complex magnetosphere-ionosphere- thermosphere (M-I-T) system have been proposed over the years to increase the accuracy of empirically and/or physically based climatological models by combining observations during a period of interest with background models. The evolution of the mapping and modelling approaches were expected to provide reliable results and improve ionospheric prediction, specification, and forecasting on the condition of there being sufficient satellite and ground-based observational data. Earlier studies established that different data-based models can produce different results under the same solar-terrestrial conditions, resulting in certain limitations for a range of applications. One approach to overcoming these limitations was the parallel development of a number of regional and/or local ionospheric models, aiming to better understand the Earth's upper atmosphere and the role of micro- and meso-scale processes in controlling the global M-I-T system. In practical terms, these rather simplistic models aimed to attain a predictive capability for the processes in the $\mathrm{M}-\mathrm{I}-\mathrm{T}$ system that most directly affect modern-day technological applications. Regional and local mapping and modelling was recognized as a crucial element 


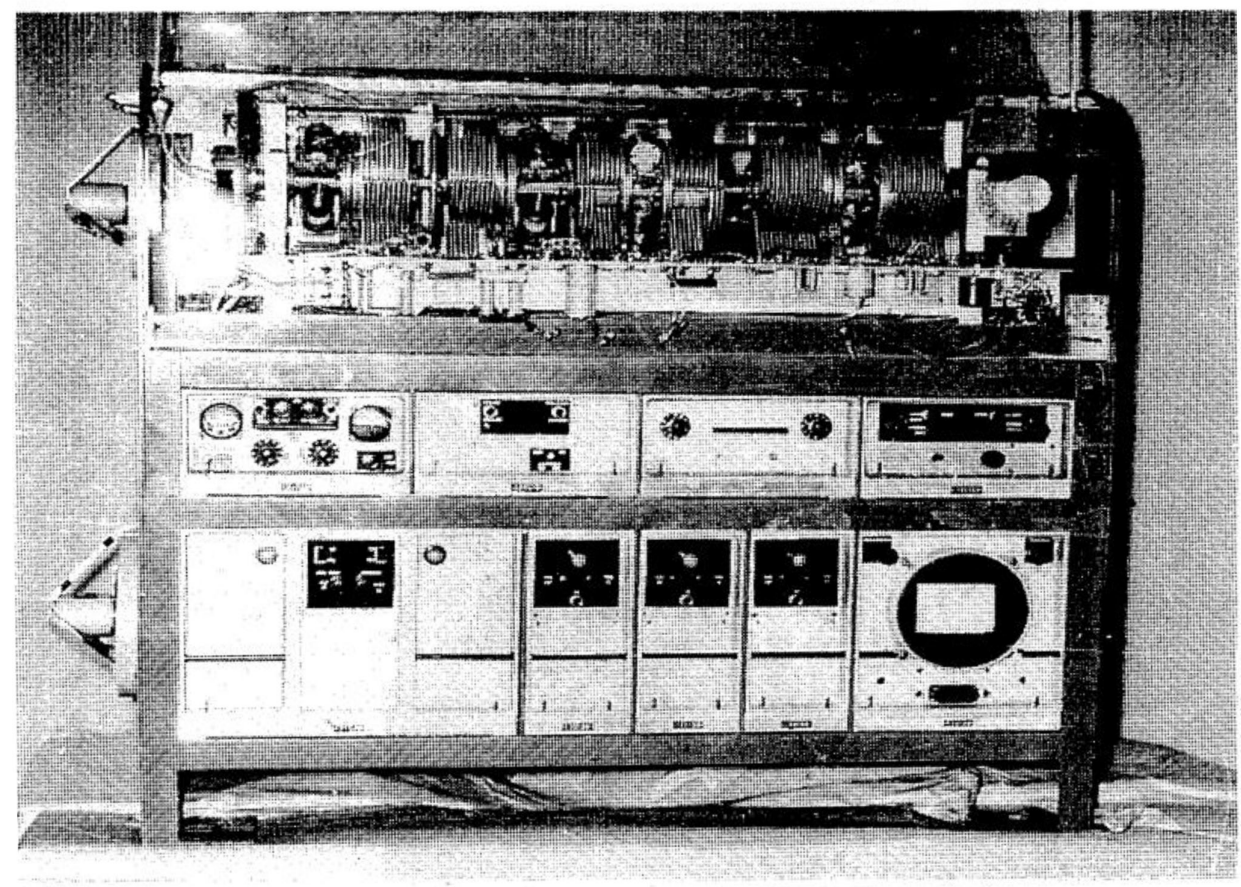

Figure 1. Antique ionosonde still in use during the 1970s.

for integrating new observations into global 3-D ionospheric models of the most significant ionospheric characteristics, such as critical frequencies, total electron content, and electron density profiles. This became an important goal for the ionospheric COST (European Co-operation in Science and Technology) Actions from 1991 to 2008.

Section 2 describes the role of COST Actions in unifying the European ionospheric community in the period spanning the two millennia and the resulting achievements. This is divided into two subsections as follows: the historical context for ionospheric measurements and HF radio propagation predictions and the associated need for global and regional ionospheric mapping (Sect. 2.1); and the details of the COST framework for European collaboration, with emphasis on ionospheric issues (Sect. 2.2). Section 3 presents the main results from the specific new studies that were derived from four ionospheric COST Actions: 238 (Prediction and Retrospective Ionospheric Modelling over Europe - PRIME); 251 (Improved Quality of Service in Ionospheric Telecommunication Systems Planning and Operation); 271 (Effects of the Upper Atmosphere on Terrestrial and Earth-Space Communications); and 296 (Mitigation of Ionospheric Effects on Radio Systems - MIERS). This can be considered as a state-of-the-art summary for ionospheric COST Action achievements. Section 4 provides information on contemporary ionospheric monitoring and modelling, real-time monitoring capacity building products, services, networking, and outreach programmes. Section 5 summarizes the main points of this paper, and the extensive list of references draws atten- tion to numerous special volumes and/or issues in international journals devoted to the scientific and technical results and achievements of COST Actions in great detail.

\section{Ionospheric science in Europe at the end of last century}

\subsection{Historical context of ionospheric measurements and HF propagation prediction}

During the first half of the past century ionospheric research was dominated by an adventurous exploration of this portion of the terrestrial atmosphere in an attempt to understand ionospheric phenomena and the physical mechanisms involved, and by the first theoretical assessment of radio propagation in ionized media (Appleton, 1928; Ractliffe, 1962). These studies were strongly motivated and adequately financed in countries with global interests that made long distance HF radio communication applications particularly useful (Anduaga, 2009; Zolesi and Cander, 2014).

The years after the Second World War were characterized by the activities of important international organizations, like the International Union of Radio Science (URSI), the Committee on Space Research (COSPAR), and in particular the International Radio Consultative Committee (CCIR), the forerunner of the International Telecommunication Union Radio Communication Sector (ITU-R), a United Nations specialized agency. They all encouraged systematic monitoring of the ionosphere around the world using so-called 


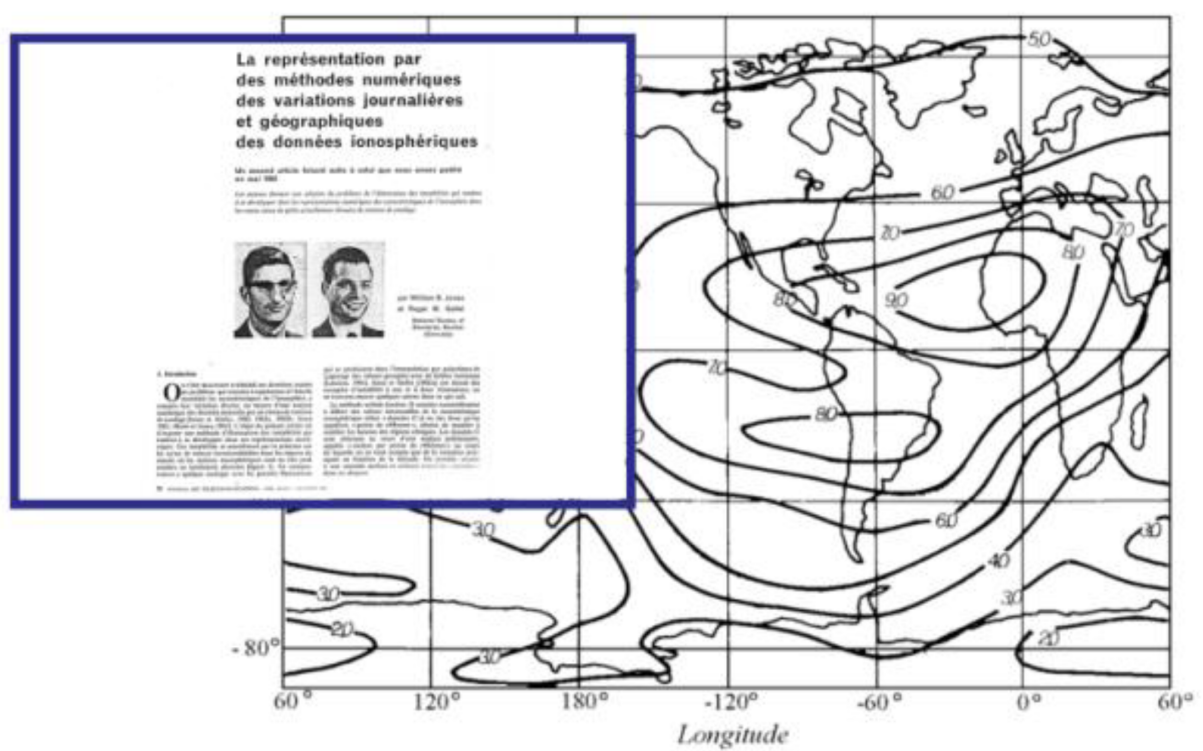

Figure 2. An example of a predicted median MUF(0)F2 map and the first page of the paper by W. B. Jones and R. M. Gallet.

ionosondes, a particular type of radar capable of detecting the electron density of the ionospheric plasma as a function of height by scanning transmissions from 1 to $20 \mathrm{MHz}$ and measuring the time delay of any echoes. Figure 1 shows an old ionosonde model characterized by its large capacitors and high levels (kilowatts) of transmitted power (Bibl, 1998). A large number of ionospheric vertical sounders were installed in numerous astronomical or geophysical observatories, achieving maximum network expansion during the International Geophysical Year (IGY) from July 1957 to December 1958.

The enormous number of observations collected during the years around the IGY, and in particular the new availability of computing devices, enabled the production of the first global maps of median monthly conditions of ionospheric characteristics, based on the maximum electron density of the ionospheric $\mathrm{F}$ region. This early development represented an important tool for applied science, radio users, and especially frequency planners at radio broadcasting agencies, as well as geophysicists studying the upper atmosphere. During this time the most successful global model for long-term mapping of two of the most important ionospheric characteristics, critical frequency of the F2 layer $(f o \mathrm{~F} 2)$ and propagation factor for a distance of $3000 \mathrm{~km}(M(3000) \mathrm{F} 2)$, was introduced by William B. Jones and Roger M. Gallet (Jones and Gallet, 1960, 1962) and it was widely applied during the last decades of the last century for long-term prediction in HF planning (Fig. 2). Important theoretical improvements on the model and new coefficients were provided later by the CCIR (International Radio Consultative Committee), while the method and mathematical structure was substantially the same as those set out in the CCIR's Atlas of Ionospheric Characteristics (1967).

The 1960s and 1970s were characterized by two key developments in the exploration of the terrestrial ionosphere and its role in telecommunications: the use of satellites for long distance communications, and the technological evolution of ground-based ionospheric observations from analogical to digital electronics. The technological evolution of electronic devices and computing systems changed the method for recording ionospheric data, shifting from the complicated use of the photographic film (Fig. 3, left) at the beginning of ionospheric history to paper (Fig. 3, right), and then to magnetic tape with the digital ionosonde or so-called digisonde (Reinisch and Huang, 1983).

The emergence of vertical-incidence digisondes and oblique-incidence CHIRP (Compressed High-Intensity Radar Pulse) sounder systems indicated how the approach was evolving towards real-time monitoring of the ionosphere, with a resulting need for or an instantaneous or at least a short-term forecasting picture of the ionosphere and the evolution of the geophysical ionosphere models. However, in the early eighties the exchange of ionospheric data between ionospheric observatories and geophysical or radio communication bodies was still mainly in the form of paper bulletins collected by World Data Centres according to the URSI rules (Piggot and Rawer, 1972). Subsequently a new generation of digisondes and ionosondes, industrial or produced in-house at ionospheric observatories, were able to collect large amounts of data in digital form. They rapidly spread around the world, changing the way of storing ionospheric data records and providing an easier means for exchanging them. 
(a)

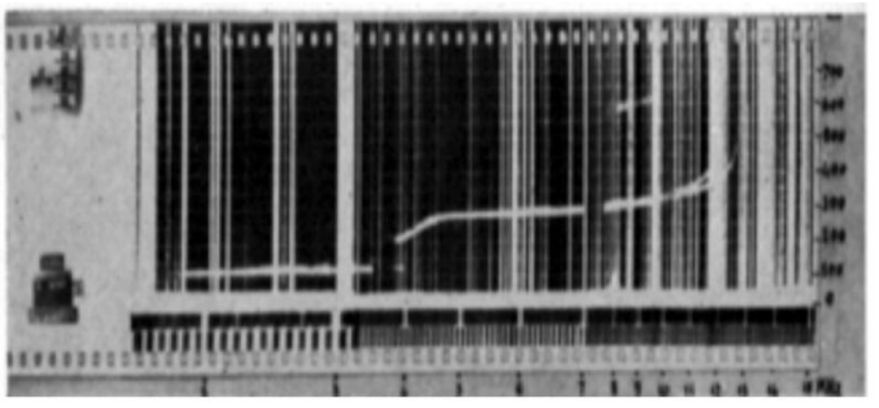

(b)

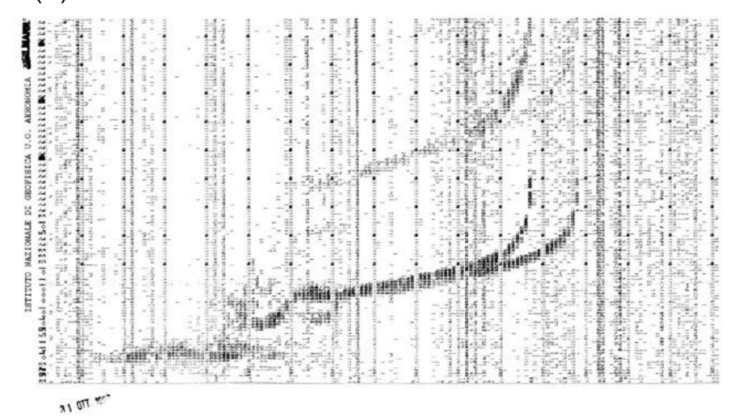

Figure 3. An old ionogram recorded on negative film is shown in (a): frequency is on a logarithmic scale. Panel (b) shows an ionogram from the first digisonde recorded on paper and tape: the intensity of the trace is proportional to the intensity of the received signal.

The revolution initiated by the digital ionosonde culminated when improvements in personal computers made it possible to implement an automatic method for interpreting ionospheric records by so-called automatic scaling. This initiated the era of space weather and real-time ionospheric monitoring by interfacing the hardware systems with the web for various geophysical, technological, and telecommunication applications (Reinisch et al., 2009; Pezzopane and Scotto, 2007).

Despite the growth of satellite communications and technological progress in ground-based and satellite ionospheric measurements, at the beginning of the 8-year period in question, the models for ionospheric mapping were mainly global and were little improved, apart from some additional coefficients based on new measurements. The IRI (International Reference Ionosphere) was still the most important model (the latest version is available at http://iri.gsfc.nasa.gov/, last access: 15 May 2018). This is the standard model of the ionosphere and for a given coordinate, time, and date it describes the electron density and ion composition. Climatological input values include electron and ion temperatures and median monthly values of $f o \mathrm{~F} 2$ and $M(3000) \mathrm{F} 2$ predicted by the socalled CCIR/URSI coefficients (Bilitza, 2001).

The IRI model was applied with great success, but the sparse and inhomogeneous geographical distribution of the observation points, in particular for the oceans and extreme habitats, remained a significant problem in ionospheric mapping and modelling.

The rapid growth in the use of satellites for long-distance communications between the end of the 1970s and the beginning of the 1980s created the false impression that HF radio communications via the ionosphere would soon become obsolete. The introduction of CHIRP sounder systems also appeared to be in competition with traditional HF radio propagation prediction models and methods. CHIRP identifies the usable frequency spectrum between two points based on an oblique ionogram with real-time frequency management. This suits the typical needs of the military who still rely heavily on HF radio communications. This caused a serious crisis in the ionospheric community, especially in European countries where the scientific activity was still concentrated within universities or government institutions. The new form of research funding from the European Union was still in its infancy and not as evolved as in more recent years. The situation was different in the United States and the former USSR due to their global interests, and also in Australia where its isolated geographical position ensured a large and important base of HF users (Fox and McNamara, 1988).

Europe instead had the longest history of ionospheric observation, the most dense distribution of ionospheric stations active for many years, frequently more than five solar cycles, and the largest database of ionospheric measurements (Fig. 4). Intense scientific research in ionospheric science was still underway in many different countries. This was well documented in a review book published by the Istituto Nazionale di Geofisica in Rome and promoted by the COST 251 Action. The book presents a collection of individual papers describing ionospheric research in each European country (Special Volume Quaderni di Geofisica, 2001).

Peter Antony Bradley (to whom this paper is dedicated) had the idea of bringing together and making this mass of data available by exploiting the new possibilities provided by modern computer systems. He proposed the first European project devoted to ionospheric research in the European scientific community, with the aim of producing a regional model of the ionosphere for long-term ionospheric prediction, forecasting, and even nowcasting with much better accuracy than the global model. This idea was first discussed in 1988 by Bodo Reinisch and Peter Bradley during an informal conversation in the United States, and then again during the second Conference of Geomagnetism and Aeronomy held at the Istituto Nazionale di Geofisica, Rome, on the 18 to 20 October 1988 (Meloni and Zolesi, 1991). The project was limited to the collection of ionospheric measurements from European Observatories and it was proposed within the framework of the European COST (CO-operation in the field of Scientific and Technical research - original name), one of the longest-running instruments supporting co-operation 


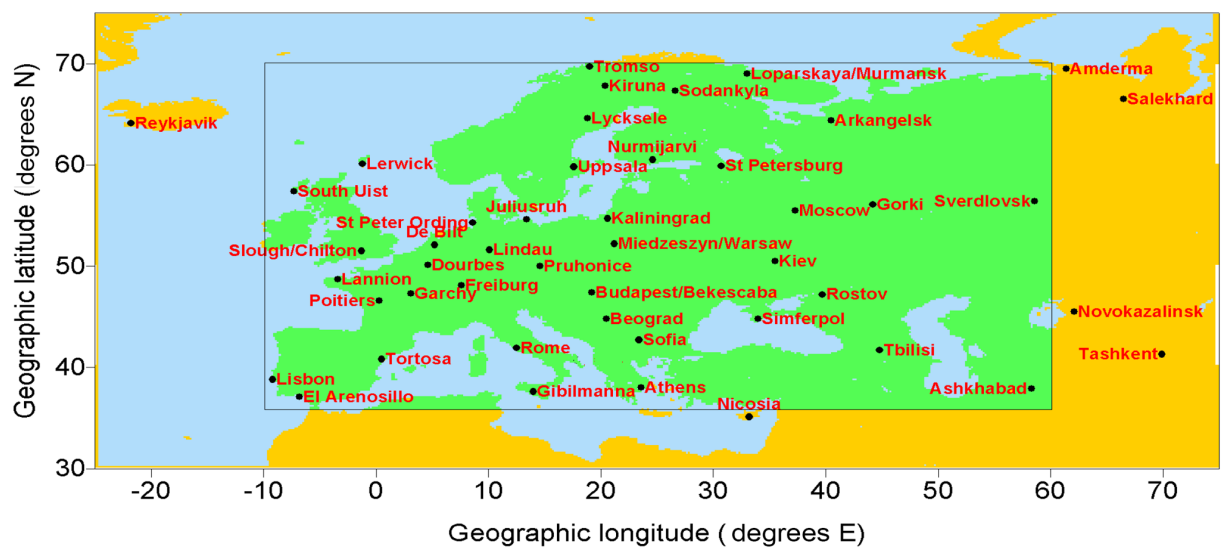

Figure 4. Map of European ionospheric vertical stations active during the IGY together to those still working.

between scientists and researchers across Europe. It was accepted and the story of the ionospheric COST Actions began.

\subsection{Ionospheric Actions within the COST framework for European collaboration}

The name COST is an acronym for "Co-operation in the field of Scientific and Technical Research", established in November 1971. The European COST framework was set up as an intergovernmental mechanism that sponsors scientific and technical co-operation and co-ordination between research teams and institutional partners from the 34 COST countries, as well as non-European institutions. The COST framework enables scientists to collaborate over a wide spectrum of research and technological initiatives, allowing co-ordination of nationally funded research on a European level. The main goal of COST is to ensure that Europe maintains a strong position in scientific and technical research for peaceful purposes, by increasing European co-operation and interaction in these areas. COST has clearly demonstrated its validity in non-competitive research, in pre-normative co-operation, and in solving environmental, cross-border issues of public utility. The COST Actions have posed important challenges for the European and worldwide ionospheric community to unite their efforts towards common goals (Fig. 5).

One of the first seven COST domains in 1971 was the Telecommunications Information Science and Technology or TIST domain in which the first ionospheric COST Action was introduced in 1991. This was the 4-year COST 238 Action, PRIME, bringing together a dynamic group of more than 150 scientists from different countries and research institutions and/or universities. The ideator and chairman was Peter A. Bradley from the Rutherford Appleton Laboratory, Chilton, United Kingdom. The objectives were to develop techniques for using ionospheric sounding information recorded by existing measuring equipment to generate improved models of the European ionosphere and im- prove the estimation of ionospheric propagation effects on telecommunication systems (Bradley, 1995).

The second ionospheric COST 251 Action was called "Improved Quality of Service in Ionospheric Telecommunication Systems Planning and Operation" and was implemented in the TIST Technical Committee domain during the period 1995-1999. The objectives of the COST 251 Action were to demonstrate the practical improvements in terrestrial and Earth-space radio systems from the COST 238derived (PRIME) ionospheric models, further refine these models, widen their geographical area of applicability between latitudes $35-70^{\circ} \mathrm{N}$ and longitudes $10-60^{\circ} \mathrm{E}$, and to promote their use. The chairman was Rudi Hanbaba from CNET (Centre National d'Eudes des Télécommunications), Lannion, France (Hanbaba, 1999).

The COST 271 Action "Effects of the Upper Atmosphere on Terrestrial and Earth-Space Communications" during the period 2000-2004 performed studies intended to guide the technical development and implementation of new communication services, particularly the GNSS and other advanced Earth-space and satellite-satellite applications. The chairman of this Action was Bruno Zolesi from the Instituto Nazionale di Geofisica, Rome, Italy (Zolesi and Cander, 2004).

The final Action of the series related to the ionospheric effects on radio communication and navigation under the TIST Technical Committee was the COST 296 Action, MIERS, during the period 2005-2009. Its objectives were to increase the necessary knowledge in order to mitigate the effects of the ionosphere on practical radio systems, allowing new and emerging methodologies and techniques to be tested on well characterized samples and implemented when appropriate. The chairpersons for this Action were Ljiljana R. Cander from the Rutherford Appleton Laboratory, Chilton, United Kingdom (2005/2006), and Alain Bourdillon from the Université de Rennes 1, Rennes, France (Bourdillon et al., 2009). 


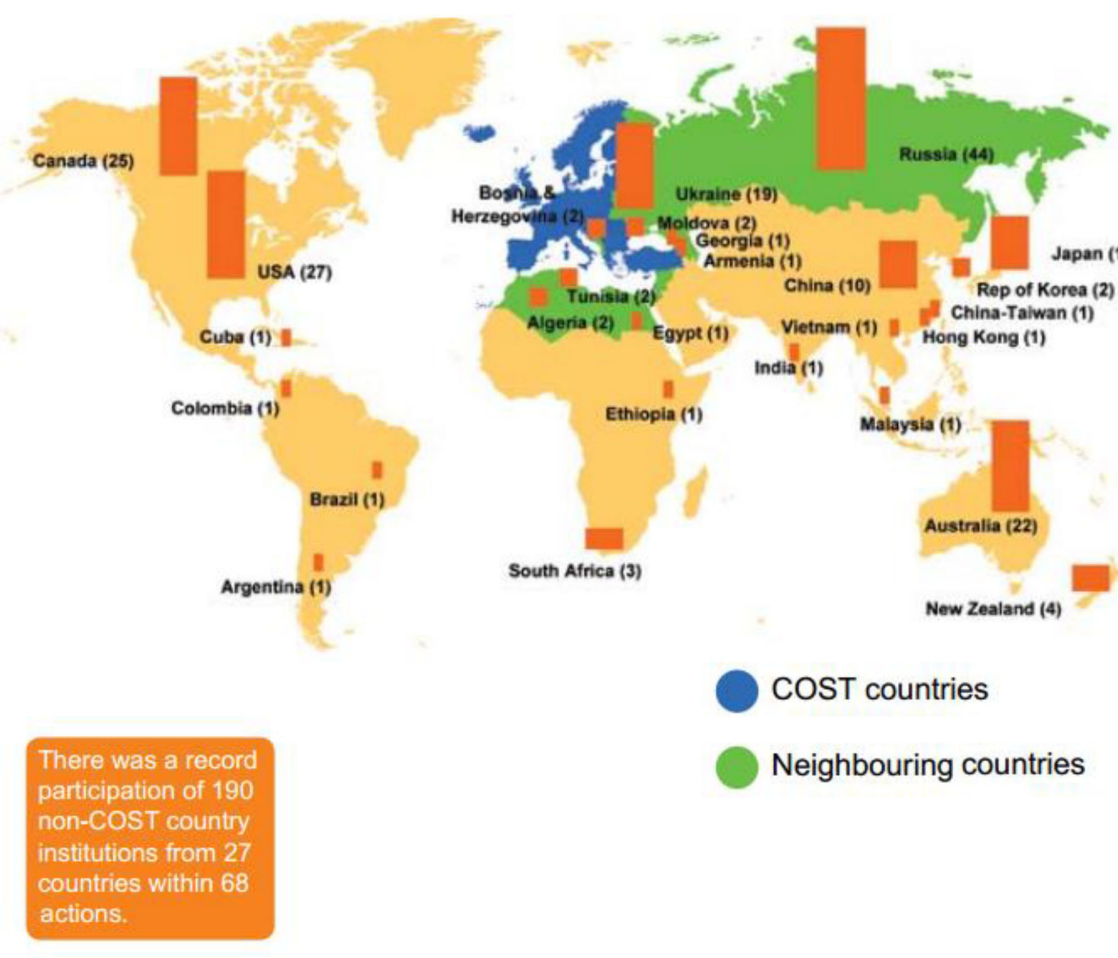

Figure 5. Map of COST, neighbouring, and non-COST countries participating in different Actions (from the COST Annual Report, May 2008, www.cost.eu, last access: 15 May 2018).

The COST member countries actively involved in the preparation of these Actions included Austria, Belgium, Bulgaria, the Czech Republic, Cyprus, France, Finland, Germany, Greece, Italy, Hungary, Poland, Portugal, Spain, Sweden, Turkey, and the United Kingdom. The following nonCOST institutions were actively involved in the preparation of the Actions: the University of Massachusetts Lowell, United States; St Petersburg State University, St Petersburg, Russia; the IZMIRAN, Moscow, Russia; the Polar Research Institute of China, Shanghai, China; and the China Research Institute of Radio Wave Propagation, Beijing, China.

The activities of these four COST Actions generated a large number of technical reports and scientific papers in the international literature, as well as a few special volumes published within important international scientific journals and derived from special sessions at international conferences like the European Geophysical Union, the COSPAR, and the URSI. Joint workshops were organized with the IRI community with extremely important close collaboration between IRI members and European scientists. Particular attention was paid to dedicated schools and training courses for young scientists, and numerous internal workshops, at least two per year, were assigned to the presentation and evaluation of the Action results.
3 Twenty years of ionospheric science promoted by four COST Actions in Europe: main scientific results

\subsection{Regional ionospheric models: evolution and refinement of new models and impartial testing procedures during the COST 238 and 251 Actions}

The primary objectives of the first COST Action were to develop predicted and retrospective models of the ionosphere over Europe, between latitudes $35-55^{\circ} \mathrm{N}$ and longitudes $10^{\circ} \mathrm{W}-30^{\circ} \mathrm{E}$, with improved accuracy of existing international procedures. This was clearly expressed in the words forming its acronym: "Prediction and Retrospective Ionospheric Modelling over Europe" (PRIME). The COST 238 participants performed very well in the collection and definition of an initial database of ionospheric measurements from 27 ionospheric stations in the European region, stored on an optical digital disk and including additional data from special vertical and oblique sounding campaigns carried out during the Action. These data formed a useful foundation for the specification of a new model, and for the testing procedure applied to rank the proposed new models.

A large number of new methods were proposed during the COST 238 Action and then developed and refined in the COST 251 Action. These intended to improve the performance of ionospheric mapping of the principal ionospheric characteristics $f o \mathrm{~F} 2, M(3000) \mathrm{F} 2$, and total electron content 
(TEC). There were also models for electron density profiling in retrospective studies, long-term prediction, and instantaneous specification over a restricted area like Europe. Some of the techniques previously developed for worldwide mapping were adjusted for application over restricted regions, while the single station models (SSMs) were instead considered valid only over a limited area, whatever simple or complex applications they served. Among these it is important to mention the MQMF2R method developed by A. Mikhailov for the median monthly values of $f o \mathrm{~F} 2$, and the UNDIV method developed by R. Leitinger for the median monthly mapping of $M(3000) \mathrm{F} 2$, which produced the best results according to the applied test procedure. Details and references for the two methods are provided in the COST 271 final report (Hanbaba, 1999).

The MQMF2R model was based on a multiquadratic method and originally developed for mapping worldwide monthly median $f o \mathrm{~F} 2$ values, and then subsequently adapted for regional and instantaneous mapping. The multiquadratic MQMF2-IM method was further extended to instantaneous mapping of the new ionospheric index MF2, and commended by the COST Actions for its good performance (Zolesi and Cander, 2014).

The UNDIV model is a simple long-term mapping procedure that assumes a parabolic dependence of $f o \mathrm{~F} 2$, and a linear dependence of $M(3000) \mathrm{F} 2$, on the solar index $R_{12}$. It is also based on a bilinear regression analysis in latitude and longitude of the hourly median values of the $f o \mathrm{~F} 2$ and $M(3000) \mathrm{F} 2$ ionospheric characteristics available over a defined region. The COST 238 Action recommended this method for application over the European area for both $f_{o} \mathrm{~F} 2$ and $M(3000) \mathrm{F} 2$, while the COST 251 project, after testing it against other newly developed methods, adopted it only for $M(3000) \mathrm{F} 2$.

An impartial test procedure was conducted using a common database in order to rank the modelling techniques presented during these two Actions, identifying the methods that performed best or at least provided better results than the global models. It is important to underline that this was the first time the performance of methods were tested by a different team of researchers from the authors, and using different data from those used to generate the models' numerical coefficients.

The joint participation of the COST Actions community at the International Reference Ionosphere Workshops generated an excellent synergy between the two projects and a significant increase in scientific results regarding the electron density profile $N(h)$. In line with the aims of the collaborations promoted by the COST Actions, various task forces dedicated to this subject were organized at the International Centre for Theoretical Physics of Trieste.

Another important task of the initial COST Actions was so-called "instantaneous mapping", when simultaneously measured values are used to design a real-time map of ionospheric characteristics (nowcasting), historic data sets (retro-

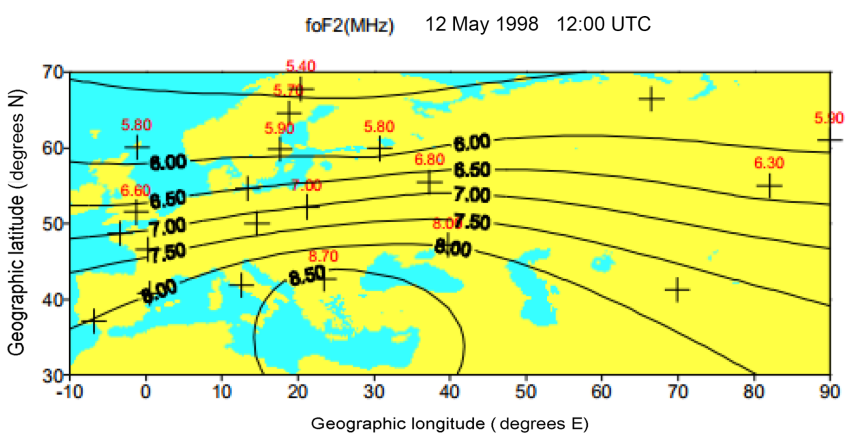

Figure 6. Map derived from measured values of $f_{0} \mathrm{~F} 2$ for 12 May 1998 at 12:00 UT.

spective mapping), or short-term predicted values for forecast mapping. Instantaneous mapping methods are mainly based on contouring techniques, and one of the most widely used and applied in the COST Actions was the Kriging procedure, a geostatistical interpolation technique first introduced in mine engineering by D. G. Krige (Oliver and Webster, 1990). The Kriging method was successfully used to spatially interpolate derived $f o \mathrm{~F} 2$ and $\mathrm{MUF}(3000) \mathrm{F} 2$ characteristics from a sparse network of ionospheric sounder observations. Figure 6 shows an example of measurement maps of foF 2 for 12 May 1998 at 12:00 UT, with the crosses indicating measured values at ionosonde stations. Different ionospheric conditions are represented over the area of -10 $90^{\circ} \mathrm{E}$ in longitude and $30-70^{\circ} \mathrm{N}$ in latitude (Dick et al., 1999). Other important scientific issues were studied and discussed in depth. These included the question of which solar index should be applied in the new methods developed since the first meeting. The clear favourites were the $R_{12}$, the monthly running mean of the solar sunspot number, or the ionospheric variability of ionospheric characteristics hour by hour, or within an hour, an issue that has become increasingly relevant.

Scientists from eastern Europe and Russia made important contributions to the final results. They began collaborating in the COST Actions in the early 1990s on the strength of the political changes during those years, rapidly becoming an important part of the European ionospheric community. The late 1980s and early 1990s also witnessed a rapid spread of personal computers, and different computer programs were elaborated during the first two COST Actions to provide ionospheric prediction and forecasting for a greater number of ionospheric characteristics under a wider variety of solar-terrestrial conditions (Hanbaba and Zolesi, 2000).

\subsection{Toward the new millennium and a new renaissance of European ionospheric science with COST 271 and COST 296}

The beginning of the new millennium saw huge developments in technologies related to advanced terrestrial- and 
space-based systems in general, and ionospheric measurements and data support facilities and infrastructure in particular. Consequently, the keywords in the title of COST 271 were "space weather" as astutely noted by Bradley and Reinisch in their paper "Impact of COST 271" (2004). A1though dedicated studies had made significant steps in the emerging science of the impact of space weather on the terrestrial environment and advanced technology, many more issues relevant to the performance of telecommunication and navigation systems were addressed by the large number of participants worldwide in the COST 271 Action. In brief these involved a range of areas: nowcasting, forecasting, and warning tools; methods and supporting databases for predicting ionospheric propagation; total electron content variations and their application in the reconstruction of plasmasphericionospheric structures as a key parameter for navigation errors in GNSS applications; and the effects of planetary and gravity waves, and electron density gradients, on terrestrial and satellite communications.

Access to real-time information on ionospheric conditions over Europe was required for high-frequency communications, satellite-ground links, and solar-terrestrial research. This was enhanced during both the COST 271 and COST 296 Actions using a network of vertical ionosondes and including as many European stations as possible. The COST 271 community provided active support by setting up a unified database of detailed ionospheric vertical sounding observations from across Europe, named the Prompt Ionospheric Database at Rutherford Appleton Laboratory (https://www.ukssdc.ac.uk/prompt_database.html, last access: 15 May 2018), which was also a desideratum of the ITU (Question ITU-R 222-1/3). A valuable database of EISCAT (European Incoherent SCATter) observations from 1981 to 1999 was established at the University of Grenoble and was available to the ionospheric COST community. The GPS-based regional maps and the TECEDA databank were made available at the Deutsches Zentrum für Luft und Raumfahrt (Zolesi and Cander, 2002; Zolesi et al., 2007).

Together with the newly developed mathematical methods and computational tools for modelling and regional mapping of ionospheric characteristics and parameters, associated added value services continued operation at the permanent general admission web-based source of the Rutherford Appleton Laboratory and the Regional Warning Centre in Warsaw (http://www.cbk.waw.pl/rwc, last access: 15 May 2018) . These included real-time nowcasting and forecasting of the state of the ionosphere over Europe, and warnings for extreme variability. The aim was to provide international ionospheric, space weather, and user communities with more accurate forecasts for telecommunications and the means to correct for ionospheric effects on navigation systems.

The availability of extensive 3-D time-varying ionospheric data enabled studies to extend knowledge of the structure and dynamics of the Earth's upper atmosphere and develop effective theoretical and numerical instruments to permit

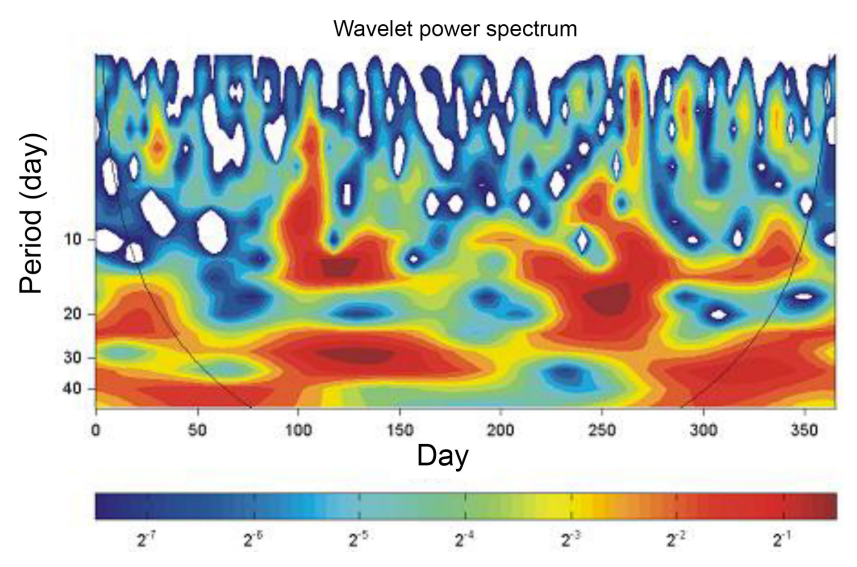

Figure 7. Planetary wave activity inferred from $f o \mathrm{~F} 2$ for Průhonice, January-December 1980 with Morlet wavelet and Fourier spectrum: horizontal axis - power; vertical axis - period of oscillations in days (Bremer et al., 2009).

investigation of the complex magnetosphere-ionospherethermosphere interactions under various geophysical conditions. Unexplained ionospheric extreme cases typically involve high or low electron content values, anomalous gradients and variations attributed to ionospheric storms, gravity and planetary waves at European mid-latitudes with associated travelling ionospheric disturbances (TIDs) and spread $\mathrm{F}$ phenomena, and the behaviour of the F1 and sporadic E layers under geomagnetic storm conditions. These were studied to define as closely as possible the residual uncertainty in ionospheric radio-wave propagation predictions (Fig. 7). The understanding was improved of the physical mechanisms responsible for possible long-term trends in the Earth's ionospheric and atmospheric parameters, possibly linking these trends to anthropogenic activities (Boska et al., 2003; Lastovicka et al., 2003; Bremer et al., 2009).

Algorithms and software tools were developed to deal with disturbances in Earth-space and satellite-satellite communications, including models to assess the effects of higher order ionospheric propagation errors in advanced ground-based applications and ionospheric influences in the use of GNSS occultation for stratosphere/troposphere applications, and to establish the statistical characteristics of transmitted signals, in particular scintillation indices, fade duration, and cumulative probability of a signal using a global map of scintillation indices (Global Ionospheric Scintillation Model, GISM). Of particular importance were measurements and simulations regarding the propagation of HF radio waves over northern European paths, where ionospheric effects cause marked Doppler and delay spreads in propagating signals.

Reviewing an earlier series of important ionospheric COST Actions after the telecommunications industry broadened its scope to encompass this sphere inevitably raised a number of new issues related to the observation, modelling, and simulation of rapidly changing natural phenomena in 


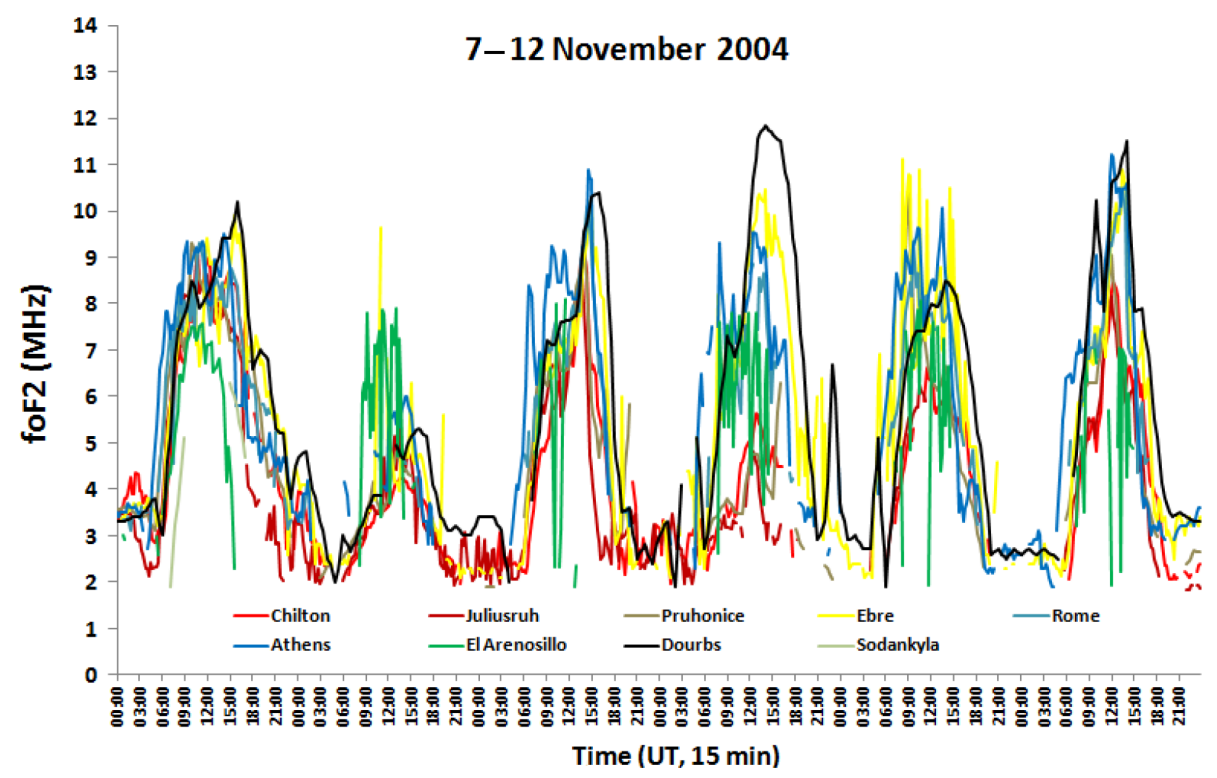

Figure 8. Time variations in $f o \mathrm{~F} 2$ at Chilton $\left(51.6^{\circ} \mathrm{N}, 358.7^{\circ} \mathrm{E}\right)$, Juliusruh $\left(54.6^{\circ} \mathrm{N}, 13.4^{\circ} \mathrm{E}\right)$, Pruhonice $\left(50.0^{\circ} \mathrm{N}, 14.6^{\circ} \mathrm{E}\right)$, Ebre $\left(40.8^{\circ} \mathrm{N}\right.$, $\left.0.5^{\circ} \mathrm{E}\right)$, Rome $\left(41.9^{\circ} \mathrm{N}, 12.5^{\circ} \mathrm{E}\right)$, Athens $\left(38.0^{\circ} \mathrm{N}, 23.6^{\circ} \mathrm{E}\right)$, El Arenosillo $\left(37.1^{\circ} \mathrm{N}, 353.2^{\circ} \mathrm{E}\right)$, Dourbes $\left(50.1^{\circ} \mathrm{N}, 4.6^{\circ} \mathrm{E}\right)$, and Sodankyla $\left(67.4^{\circ} \mathrm{N}, 26.6^{\circ} \mathrm{E}\right)$ during space weather events over the period 7-12 November 2004.

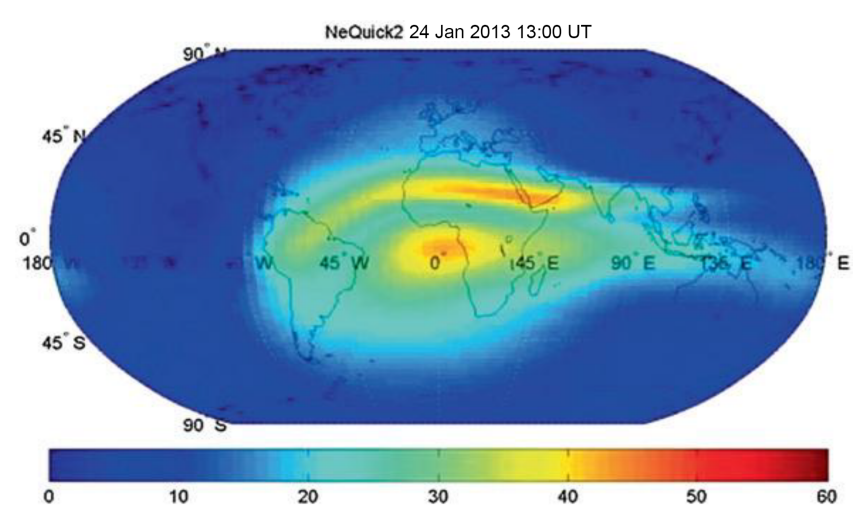

Figure 9. An example TEC map computed with NeQuick (http: //t-ict4d.ictp.it/, last access: 15 May 2018. Bottom scale is in TECU -1 TEC unit $=10^{16}$ electrons $\mathrm{m}^{-2}$ ).

space and time. Figure 8 shows an example of a rapidly changing critical frequency $f o \mathrm{~F} 2$ over European ionosonde stations during a severe geomagnetic storm, one of several space weather events starting on 7 November 2004 at 18:27 UT. The foF 2 measured by the ionosondes corresponds to the maximum plasma electron density and determines the maximum usable frequency (MUF) available to HF circuits. A significant decrease in ionization on 8 November and subsequent increase 2 days later illustrates how extremely difficult it is to predict/forecast the occurrence of $f o \mathrm{~F} 2 / \mathrm{MUF}$ changes in general, and their magnitude in particular. This huge ionospheric variability in time and space from one ionospheric station to another within the limited European area, only partly but clearly illustrated in Fig. 8, creates many prac- tical problems and strongly motivates efforts towards mitigation. With existing capabilities, and exploiting the immense potential of digital signal processing and flexible equipment, it is possible to design and implement systems that can modify propagation parameters adaptively in response to changing channel conditions, based on foreseen modelling techniques suitable for use in HF communication networks. The COST programme provides a unique framework for carrying forward this work within the European area with collaborative research into the mitigation of propagation effects on practical communications systems. Consequently, one of the main objectives of the COST 296 Action, MIERS, during the period 2005-2009, was to enhance the areas of expertise that had already been developed during previous Actions. This involved strengthening effective co-operation between ionospheric scientists on the one hand and user communities on the other, focusing the research and development undertaken in previous COST ionospheric related studies on the mitigation of ionospheric effects on specific user radio systems, some already in operation and others in the development stage of new-generation systems operating in, or affected by, the near-Earth plasma environment.

The 4 years of the COST 296 Action saw further theoretical and numerical modelling efforts together with systematic high-resolution measurements and near-real-time data access. This provided radio system planners and designers with a better understanding of the Earth's upper atmosphere and its effects on terrestrial communications and Earth-space communications, including navigational systems. It also enabled more accurate determination of the effects of the upper atmosphere on received signal and interference levels. It 


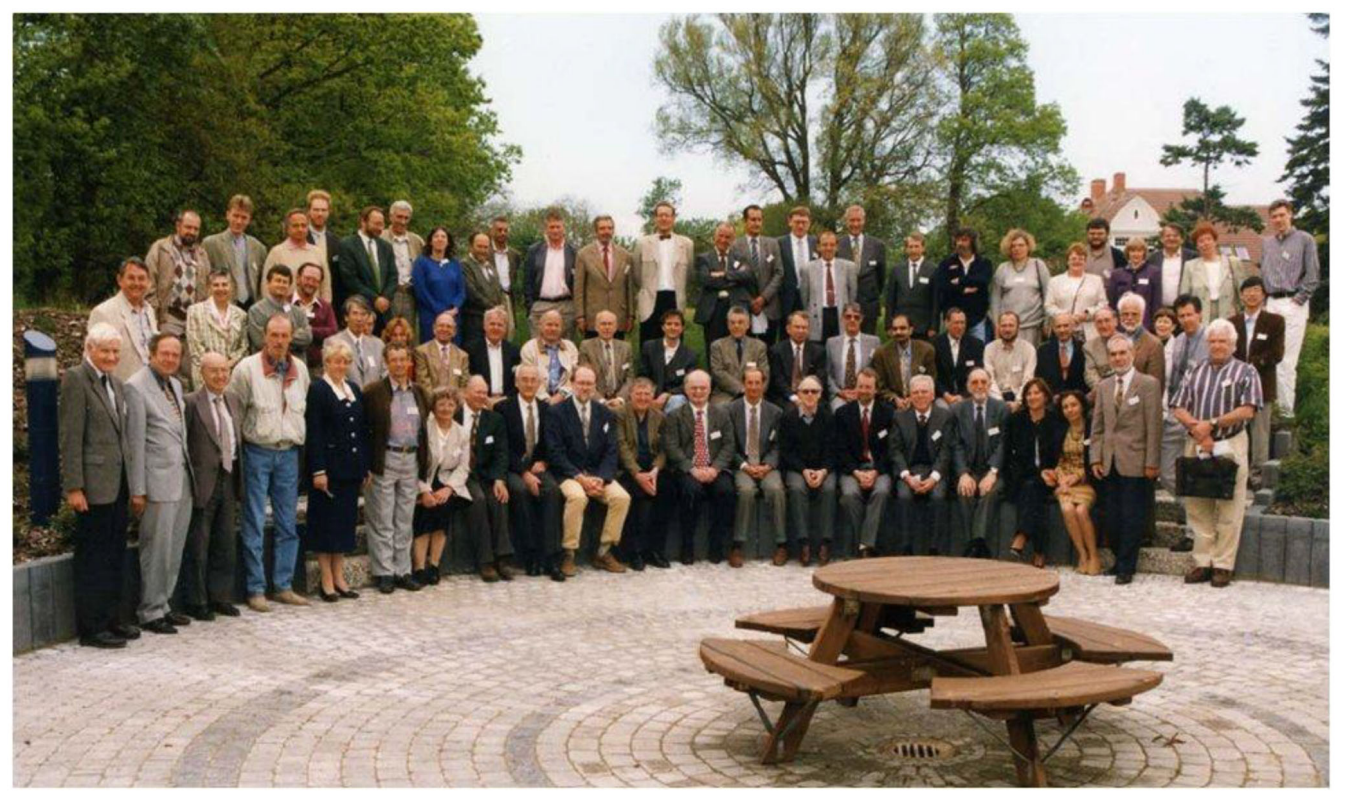

Figure 10. Group photo of participants at the joint IRI-COST 251 meeting held at the Institute of Atmospheric Physics of Kühlungsborn, Germany, in May 1997. Henry Rishbeth, Peter Antony Bradley, and Karl Rawer are respectively the first, second, and eighth from the left in the first row.

was also possible to continue the very important collection of ionospheric measurements in order to establish precursor information relevant to long-term global warming changes, in view of their consequences for the natural environment (Stanislawska et al., 2009).

The main benefits of the activities within the COST 296 Action on general telecommunications systems were addedvalue products to predict and/or correct for ionospheric effects, with an attempt to identify common patterns in each specific radio application. A good example from among many others of equal standing is the NeQuick model - an ionospheric electron density model developed at the Aeronomy and Radiopropagation Laboratory of the Abdus Salam International Centre for Theoretical Physics (ICTP), Trieste, Italy, and at the Institute for Geophysics, Astrophysics and Meteorology (IGAM) of the University of Graz, Austria (Fig. 9). It was developed over all four ionospheric COST Actions, starting as the $N(h)$ profiler in COST 238, developed as the COSTprof model in the COST 251 Action, and refined as the NeUoG-plas model in COST 271. The current versions are as follows: (a) NeQuick (v1), adopted by Recommendation ITU-R P.531 as a procedure for estimating TEC; (b) NeQuick 2, recommended by ITU (http://t-ict4d. ictp.it/nequick2, last access: 15 May 2018) and adopted by the IRI (International Reference Ionospheric) model as the default option for modelling the topside ionosphere; and (c) a special version of NeQuick, adopted as the Galileo SingleFrequency Ionospheric Correction Algorithm, the performance of which was recently confirmed during in-orbit validation (Nava and Radicella, 2014, and references therein).

\section{Development and interaction with the global ionospheric community}

Having financial support for two common meetings per year dedicated to the work in progress reinforced scientific collaboration between the scientific bodies of the different $\mathrm{Eu}-$ ropean countries, fully satisfying the aims of COST. Amiable relations between the participants was an important feature of these workshops and it helped a relevant number of young ionospheric scientists to accumulate valuable experience. They were able to extend their scientific know-how, preparing the next generation of protagonists in this science for the new millennium in Europe. This was also the inspiration for organizing the 24th course of the International School of Geophysics on Ionospheric Physics and Propagation at the "Ettore Majorana" Foundation and Centre for Scientific Culture in Erice, Italy (24-29 September 2004).

The synergy and overlap of interests was particularly effective and dynamic with the IRI (International Reference Ionosphere), a group of ionospheric scientists who over the last 60 years have worked to improve and upgrade the standard model of the ionosphere with the support of the Committee on Space Research (COSPAR) and the International Union of Radio Science (URSI), led by Dieter Bilitza, with joint meetings organized in Europe (http://iri.gsfc.nasa.gov/, last access: 15 May 2018). Figure 10 is a group photo of the participants at the joint IRI and COST 251 meeting held in May 1997 at the Institute of Atmospheric Physics of Kühlungsborn, which was particularly important because it was the first COST meeting held in Germany after its reunifica- 

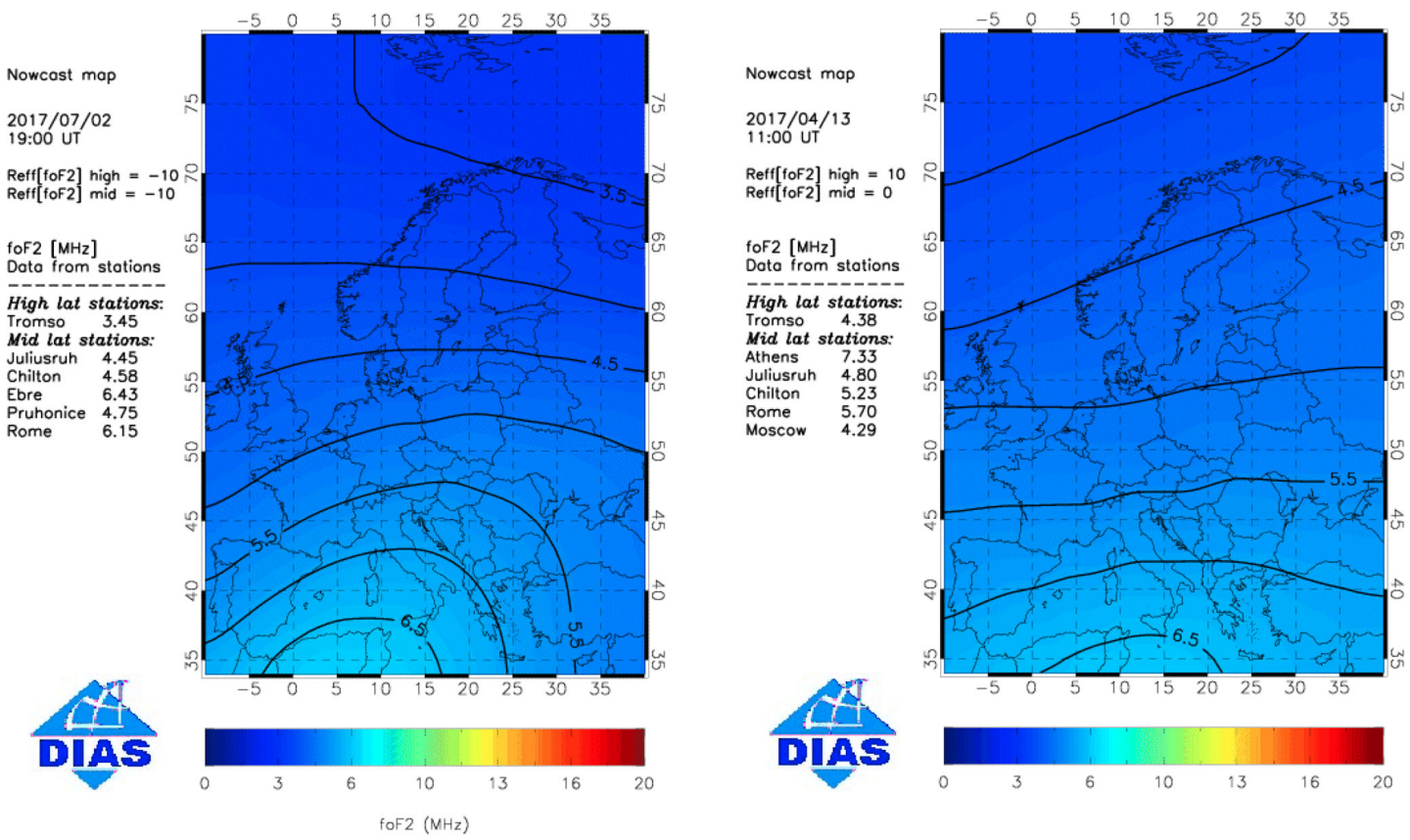

Figure 11. Examples of hourly foF2 nowcast maps predicted by SIRM and SIRMUP in July and April 2017 for DIAS (http://www.iono. noa.gr/Dias/, last access: 15 May 2018).

tion, and because all the leading protagonists of ionospheric science in Europe of the period, both old and new generations, were present. In addition to Peter Antony Bradley, it is also worth remembering Henry Rishbeth and Karl Rawer (eighth from the left in the front line of the photo).

By the end of the last century the general assemblies of the European Geophysical Union had assumed the form of the typical conferences known today, with special sessions dedicated to the dissemination in Europe of the scientific results of the COST Actions 251, 271, and 296. At the same time, the strong presence of the COST community at URSI and COSPAR conferences further enhanced interaction among the global ionospheric community.

At the beginning of the new century, members of the COST 271 and COST 296 Actions generated two more COST Actions: Action 724 (Developing the Basis for Monitoring, Modelling, and Predicting Space Weather), and Action ES0803 (Developing Space Weather Products and Services in Europe) under the domain of the Earth System Science and Environmental Management (ESSEM), extending the scientific objectives to what is currently defined as space weather. This interdisciplinary focus attracted the interest and participation of a large portion of the ionospheric community already involved in the most recent ionospheric COST 271 and 296 Actions. The active interaction of this new community with the European Space Agency led to the organization of an annual meeting, the European Space Week, which within a few years became a point of reference for exchanging scientific results, not only for European scientists; it also attracted global interest, especially through a new scientific journal, the "Journal of Space Weather and Space Climate".

European science was also characterized in the new millennium by the development and success of scientific projects promoted and financially supported by the European Union. These strongly stimulated co-operation between governments, academics, and industrial bodies from different countries in the European Union, acting towards shared goals.

One of the outcomes of the co-operation and the shared research initiated during the COST Actions was a large number of proposals for new initiatives by the participants, submitted to the European institutions.

Worthy of note among these was the DIAS, European DIgital upper Atmosphere Server (DIAS) (available at http: //www.iono.noa.gr/Dias/, last access: 15 May 2018), led by Anna Belehaki from the National Observatory of Athens. Here the measurements from most of the ionospheric vertical sounding systems active in the countries participating in the COST Actions were coordinated to generate maps of the ionospheric conditions over Europe. The same mapping algorithms and methods developed during the COST Actions were implemented in online services developed in this project, and they were also integrated into another important project, ESPAS, the near-Earth space data infrastructure for e-Science, led by Mike Hapgood from the Rutherford Appleton Laboratory (https://www.espas-fp7.eu/, last access: 15 May 2018), involving both ionospheric and space weather communities. Figure 11 gives an example of hourly $f_{o} \mathrm{~F} 2$ nowcast maps generated by the SIRM and SIRMUP 
models (Zolesi et al., 2004) in July and April 2017 for DIAS applications.

While designed to meet the needs of Europe, COST Actions have also made an impact on the international work of ITU-R, making contributions to the latter organization's recommendations, providing data for validation of prediction models, and playing a leading role in the Working Party on Ionospheric Propagation.

Close links have also been established with several organizations that deal with GNSS applications for navigation and surveying. There is a strong involvement of COST Action members in ESA/ESTEC projects: (a) concerning EGNOS and GALILEOSAT, and (b) in connection with assessment studies for the use of GNSS occultation for atmospheric and ionospheric research. The URSI Beacon Satellite Group is also linked closely to the work of the ionospheric COST Actions, establishing important contact between upper atmosphere scientists, engineers, and users of satellite beacon applications. Several COST members are advisers and observers in the International Geodynamics Service (IGS) and offspring organizations such as the GPS-IONO group.

\section{Conclusions}

The ionospheric projects within the COST framework have involved bottom-up efforts by many devoted scientists, engineers, and supporting technical and administrative staff. They provided and shared historical and near-real-time data collected in routine and special vertical and oblique ionosonde sounding campaigns over Europe. They also studied and explained the physical and chemical processes of space plasma, developed methods and algorithms to map and model variable features of the Earth's upper atmosphere climatology and weather, and implemented accumulated knowledge in practical tools, products, and web services for customers in diverse scientific fields and technologies. The scientific findings and results were published in technical reports and national or international journals.

The initial aim had been to improve the mapping of the two ionospheric characteristics, $f o \mathrm{~F} 2$ and $M(3000) \mathrm{F} 2$, most relevant for $\mathrm{HF}$ radio communications over Europe, by a relatively small group of scientists led by Peter A. Bradley. However, over more than 20 years of close collaborative work by numerous figures in four ionospheric COST Actions, the research area expanded into many other aspects of the Earth's ionosphere and beyond. Such an exhilarating outcome demonstrates how valuable it is to have the support of a framework like COST in the EU context. It also shows how important it will be to keep the scientific community together in future Actions and not allow it to fragment again into isolated scientific institutions. This is a particularly pressing issue, considering that continuous high-resolution real-time monitoring of the Earth's environment, and warnings of potentially extreme conditions that could damage the advanced modern technology upon which society depends, will certainly become even more important in years to come.

Over the last century the study and monitoring of the ionosphere was important for connecting people by long distance HF radio communications. Nowadays this is still relevant, representing a cheap and natural way to use an infinite medium. Detailed knowledge of the Earth's ionosphere is equally as important for the problems it induces in global satellite navigation as for a possible interaction between the lithosphere and the ionosphere, which could be relevant for earthquake prediction. In these cases, as in all branches of geophysics, good measurements and monitoring are like good wines: the older they are, the better they get (Pietro Dominici, personal communication, 2000).

Data availability. Vertical incident data can be accessed via the COST 271 Action Prompt Ionosphere Database, which has been created by the UK Solar System Data Centre at the STFC Rutherford Appleton Laboratory, at the following URL: https://www. ukssdc.ac.uk/prompt_database.html.

Competing interests. The authors declare that they have no conflict of interest.

Edited by: Kristian Schlegel

Reviewed by: Richard Thompson and one anonymous referee

\section{References}

Anduaga A.: Wireless \& Empire, Oxford University press, 386 pp., 2009.

Appleton, E. V.: Some notes on wireless methods of investigating the electrical structure of the upper atmosphere I, Proc. Phys. Soc., 41, 43-59, 1928.

Bibl, K.: Evolution of the ionosonde, Ann. Geofis., 41, 667-680, https://doi.org/10.4401/ag-3810, 1998.

Bilitza, D.: International Reference Ionosphere 2000, Radio Sci., 36, 261-275, 2001.

Boska, J., Sauli, P., Altadill, D., Sole, G., and Alberca, L. F.: Diurnal variation of the gravity wave activity at midlatitudes of ionospheric F region, Stud. Geophys. Geod., 47, 579-586, 2003.

Bourdillon, A., Cander, Lj. R. and Zolesi, B.: COST 296 MIERS: conclusion, COST 296 Final Report, Ann. Geophys.-Italy, 52, 209-220, 2009.

Bradley, P. A.: PRIME (Prediction and Retrospective Ionospheric Modelling over Europe), COST Action 238 Final Report, Commission of the European Communities, Brussels, 1995.

Bradley, P. A. and Reinisch, B. W.: Impact of COST 271, Ann. Geophys.-Italy, Supplement, 47, 1295-1299, 2004.

Bremer, J., Laštovička, J., Mikhailov, A. V., Altadill, D., Bencze, P., Burešová, D., De Franceschi, G., Jacobi, C., Kouris, S., Perrone, L., and Turunen E.: Climate of the upper atmosphere, Ann. Geophys.-Italy, 52, 77-101, 2009. 
CCIR Atlas of Ionospheric Characteristics: Comité Consultatif International des Radiocommunications, Report 340-4, International Telecommunications Union, Geneva, 1967.

Dick, M. I., Levy, M. F., Cander, Lj. R., Kutiev, I., and Muhtarov, P.: Short-term ionospheric forecasting over Europe, IEE Conf. Publ., 461, 105-107, 1999.

Fox, M. W. and McNamara, L. F.: Improved World-Wide Maps of Monthly Median foF2, J. Atmos. Terr. Phys., 50, 1077-1086, 1988.

Jones, W. B. and Gallet, R. M.: Ionospheric mapping by numerical methods, Telecommun. J., 12, 260-264, 1960.

Jones, W. B. and Gallet, R. M.: The Representation of Diurnal and Geographic Variations of Ionospheric Data by Numerical Methods, Telecommun. J., 29, 129-147, 1962.

Hanbaba, R.: Improved quality of service in ionospheric telecommunication systems planning and operation, COST Action 251 Final Report, Space Research Centre Printing Office, Warsaw, 1999.

Hanbaba, R. and Zolesi, B.: Improved Quality of Service in Ionospheric Telecommunication Systems Planning and Operation: Cost 251 Major Achievements, Fisica de la Tierra, 61-103, December 2000.

Lastovicka, J., Krizan, P., and Novotna, D.: Persistence of planetary waves in the lower ionosphere, Stud. Geophys. Geod., 47, 161$172,2003$.

Meloni, A. and Zolesi, B. (Eds.): Atti del II Convegno di Geomagnetismo e Aeronomia, Istituto Nazionale di Geofisica, Roma 1820 Ottobre 1988, 109-143, 1991.

Nava, B. and Radicella, S. M.: The NeQuick model: characteristics and uses, IGS Workshop - Celebrating 20 Years of Service Pasadena, 23-27 June 2014.

Oliver, M. A. and Webster, R.: Kriging: a method of interpolation for geographical information systems, Int. J. Geogr. Inf. Syst., 4, 313-332, 1990.

Pezzopane, M. and Scotto, C.: The automatic scaling of critical frequency foF2 and MUF(3000)F2: a comparison between Autoscala and ARTIST 4.5 on Rome data, Radio Sci., 42, RS4003, https://doi.org/10.1029/2006RS003581, 2007.

Piggot, W. R. and Rawer, K.: U.R.S.I Handbook of Ionogram Interpretation and Reduction, World Data Center A for Solar Terrestrial Physics-Report UAG-23, NOAA, Environmental Data Service, Asheville, 1972.
Quaderni di Geofisica: Ionospheric Physics and Radio Propagation over Europe: reports on national activities and co-operations, INGV, Quaderni di Geofisica, edited by: Cander, Lj. and Zolesi, B., 2001.

Ractliffe, J. A.: The Magneto-Ionic Theory and its Applications to the Ionosphere, Cambridge University Press, Cambridge, 1962.

Reinisch, B. W. and Huang, X.: Automatic calculation of electron density profiles from digital ionograms 3 , Processing of bottomside ionograms, Radio Sci., 18, 477-492, 1983.

Reinisch, B. W., Galkin, I. A., Khmyrov, G. M., Kozlov, A. V., Bibl, K., Lisysyan, I. A., Cheney, G. P., Huang, X., Kitrosser, D. F., Paznukhov, V. V., Luo, Y., Jones, W., Stelmash, S., Hamel, R., and Grochmal, J.: The New Digisonde for Research and Monitoring Applications, Radio Sci., https://doi.org/10.1029/2008RS004115, 2009.

Stanislawska, I., Lastovicka, J., Bourdillon, A., Zolesi, B., and Cander, Lj. R.: Monitoring and modeling of ionospheric characteristics in the framework of European COST 296 Action MIERS, Space Weather, https://doi.org/10.1029/2009SW000493, 2009.

Zolesi, B. and Cander, Lj. R.: Effects of the upper atmosphere on terrestrial and Earth-space communications: the new COST 271 Action of the European scientific community, Adv. Space Res., 29, 1017-1020, 2002.

Zolesi, B. and Cander, Lj. R.: COST 271 action Effects of the Upper Atmosphere on Terrestrial and Earth-space Communications FINAL REPORT, Ann. Geophys.-Italy, Supplement, 47, 915-925, 2004.

Zolesi, B. and Cander, Lj. R.: Ionospheric Prediction and Forecasting, Springer, Geophysics, 240 pp., https://doi.org/10.1007/9783-642-38430-1, 2014.

Zolesi, B., Cander, Lj. R., and Altadill, D.: From COST 271 to 296 EU actions on ionospheric monitoring and modelling for terrestrial and Earth-space radio systems, Adv. Space Res., 39, 899903, https://doi.org/10.1016/j.asr.2006.03.046, 2007.

Zolesi, B., Belehaki, A., Tsagouri, I., and Cander, Lj. R.: Real-time updating of the simplified ionospheric regional model for operational applications, Radio Sci., 39, RS2011, https://doi.org/10.1029/2003RS002936, 2004. 